\title{
Observation- and numerical-analysis-based dynamics of the Uttarkashi cloudburst
}

\author{
C. Chaudhuri ${ }^{1}$, S. Tripathi ${ }^{1,2}$, R. Srivastava ${ }^{1}$, and A. Misra ${ }^{1}$ \\ ${ }^{1}$ Department of Civil Engineering, Indian Institute of Technology, Kanpur, India \\ ${ }^{2}$ Centre for Environmental Science and Engineering, Indian Institute of Technology, Kanpur, India \\ Correspondence to: C. Chaudhuri (chiranjibchaudhuri@gmail.com)
}

Received: 26 November 2014 - Revised: 9 March 2015 - Accepted: 5 May 2015 - Published: 3 June 2015

\begin{abstract}
A Himalayan cloudburst event, which occurred on 3 August 2012 in the Uttarkashi $\left(30.73^{\circ} \mathrm{N}, 78.45^{\circ} \mathrm{E}\right)$ region of Uttarakhand, India, was analyzed. The near-surface atmospheric variables were analyzed to study the formation, evolution, and triggering mechanisms of this cloudburst. In order to improve upon the understanding provided by the observations, numerical simulations were performed using the Weather Research and Forecasting (WRF) model, configured with a single domain at $18 \mathrm{~km}$ resolution. The model was tuned using variation of different parameterizations (convective, microphysical, boundary layer, radiation, and land surface), and different model options (number of vertical levels, and spin-up time), which resulted in a combination of parameters and options that best reproduced the observed diurnal characteristics of the near-surface atmospheric variables. Our study demonstrates the ability of WRF in forecasting precipitation, and resolving synoptic-scale and mesoscale interactions. In order to better understand the cloudburst, we configured WRF with multiply nested two-way-interacting domains $(18,6,2 \mathrm{~km})$ centered on the location of interest, and simulated the event with the best configuration derived earlier. The results indicate that two mesoscale convective systems originating from Madhya Pradesh and Tibet interacted over Uttarkashi and, under orographic uplifting and in the presence of favorable moisture condition, resulted in this cloudburst event.
\end{abstract}

Keywords. Meteorology and atmospheric dynamics (convective processes; mesoscale meteorology; middle atmosphere dynamics)

\section{Introduction}

The interactions between the synoptic-scale circulation and hydrological cycle at mountains are highly complex and nonlinear in nature (Maraun et al., 2010). Even a moderate amount of rain may cause severe events in hills, e.g., flash floods and landslides (Borga et al., 2014). A cloudburst, also known as rain gush or rain gust, is an extreme form of precipitation in which a high intensity of rain falls over a localized area (Das et al., 2006). The India Meteorological Department (IMD) defines cloudburst as a rainfall event with intensity of the order of $100 \mathrm{~mm} \mathrm{~h}^{-1}$, accompanied by strong winds and lightning. It usually affects an area not exceeding $20-30 \mathrm{~km}^{2}$. The cloudbursts in India usually take place during the monsoon season over regions with a steep orography, like the Himalayan region, the northeastern states, and Western Ghats. Cloudburst takes place when moist thermodynamically unstable atmosphere faces a deep and rapid uplifting by a steep topography (Das et al., 2006). In cloudburst-like systems, the convective clouds may have a height of up to $15 \mathrm{~km}$. The Himalayan cloudbursts result from low pressure area monsoon clouds from the Bay of Bengal, carrying a huge amount of moisture over the Gangetic Plain to the Himalayas, and "bursting" into a heavy downpour $\left(75-100 \mathrm{~mm} \mathrm{~h}^{-1}\right)$ under the topographic influence. The cloudbursts generally occur in the remote hilly areas and are typically not noticed unless the resulting flash floods and landslides cause a major socioeconomic disruption. With an early prediction and warning of these events, and an appropriate training of local administration, the socioeconomic impacts of cloudbursts may be reduced. The reliability of the predictions could be increased if high-resolution measurement data $(\sim 10 \mathrm{~km})$ of meteorological parameters are provided through meso-net 
observations such as automatic weather stations (AWSs), radiosonde/radiowind (RSRW), and Doppler weather radar.

Numerical weather prediction (NWP) is useful for shortor medium-range forecasting by downscaling either the large-scale observed field or the fields derived from a global circulation model (GCM). However, the highly nonlinear, and not yet fully understood, relationships between meteorological variables and topography imply that obtaining an accurate prediction is a difficult task. The nested regional circulation model (RCM) is initialized with the coarse-resolution large-scale atmospheric fields from atmosphere-ocean general circulation models (AOGCMs) or from global reanalysis. The continuous time integration is done with frequent update of the lateral meteorological and surface boundary conditions (LBCs and SBCs). The RCM adds regional details to account for the regional-scale forcing (e.g., topography, coastline, and land use/land cover).

The resolution of the model is one of the most important factors affecting the accuracy of the forecast. Wang et al. (2004) showed that increasing the model resolution is important to improve the quality of forecasting the micro- and mesoscale systems. However, the availability of computer resources and their capability greatly constrain the increment of resolution, and it can only be increased at key regions. In this study, we have used the nested domain formulation to overcome this problem, without a significant loss of accuracy (Cheng, 1994).

Heavy rainfall events, like over Uttarkashi on $3 \mathrm{Au}-$ gust 2012, are documented for several mountain regions around the globe. One of the most devastating storms among them was the one that caused the Big Thompson flood of 1976 in Colorado. The Texas hill storm event (Caracena and Fritsch, 1983), near the town of Bluff, about $90 \mathrm{~km}$ northwest of San Antonio, had an unofficial record of a $79 \mathrm{~cm}$ accumulation of rain over $24 \mathrm{~h}$. The meteorological conditions leading to the Big Thompson flood and the 1972 Black Hills flood near Rapid City, South Dakota, are documented by Caracena et al. (1979) and Nair et al. (1997). Various types of storms with different structures and synoptic conditions can originate from convective systems (Doswell, 1985; Doswell et al., 1996; Maddox et al., 1978). Identifying and understanding the key meteorological conditions that caused the heavy rainfall events around the world can shed some light on the mechanism of such events and improve their prediction over vulnerable regions like the Himalayas.

A detailed understanding of the interaction between orographic dynamics and cloud dynamics is still lacking. Das et al. (2006) simulated the 6 July 2003 cloudburst that hit Shillagarh in Himachal Pradesh. Their study showed the capability of high-resolution numerical models (nested MM5 with highest resolution of $3 \mathrm{~km}$ in the innermost domain) in simulating cloudburst-like systems. In his report on the Leh cloud burst (2010), Ashrit (2010) investigated the evolution and intensification of that storm using high-resolution Weather Research and Forecasting (WRF) simulation with
9 and $3 \mathrm{~km}$ nested domains. Ashrit (2010) observed movement of instabilities from the Tibetan Plateau and interaction of these instabilities with the moisture-rich air from west and northwest. His finding is similar to that of Rasmussen and Houze (2012), which was derived based on available observations. These studies suggest that numerical simulation can provide useful insight into the physical process of cloudbursts.

Mesoscale processes are influenced by surface inhomogeneities in elevation, snow cover, vegetation, and surface roughness (Giorgi and Avissar, 2010). The near-surface moisture and temperature also have a major impact on the mesoscale circulations (Stefanon et al., 2014). The mesoscale weather events can be separated into two general categories on the basis of the triggering dynamics. First are the instabilities of the traveling system, which force some of the events like squall lines and mesoscale convective complexes. Second are surface inhomogeneities, which trigger some of the events like mountain or valley circulations. Many attempts have been made to explain the orographic mechanisms. Smith (1979) explained two of them: (i) stable ascent induces and enhances the stratiform precipitation, and (ii) terrain triggers and enhances the convection. Bougeault et al. (2001) studied the variety of conditions that can cause orographic rainfalls. Chen and Lin (2001) suggested that an impinging low-level jet can cause a large amount of rainfall over the upwind slope.

Though cyclonic storms, thunderstorms, and squall lines, land/sea breezes have been widely simulated by mesoscale models, the predictability of terrain-induced mesocirculations and precipitation events is debatable. Pielke (1984) pointed out that the terrain-induced mesoscale systems, being generated by a geographically fixed feature, are easier to predict than instabilities of the traveling system like mesoscale convective complexes. The deterministic physical interactions between synoptic-scale motions and the underlying local topography may increase the mesoscale predictability over a region with a complex terrain (Mann and Kuo, 1998). However, the interactions between terrain and airflow, latent heating/cooling, and uncertainties in the cloud microphysics make the simulation of precipitation over mountain areas a challenging task. The accuracy of the simulation quickly deteriorates as the integration time advances.

From an Indian perspective, the socioeconomic importance of cloudburst-like systems is huge. However, few previous studies have focused on understanding the dynamics of such systems. Our work contributes to the study of such systems with the help of observations as well as simulations. In this study we analyze the formation, triggering, and evolution of the Uttarkashi cloudburst event, which is described in the next section. The observation analysis is performed to understand the underlying mechanism, and the results are confirmed using numerical simulations. 


\section{Description of the event}

The Indian summer monsoon (June-September) has large spatial and intra-seasonal variations (Webster et al., 1998; Webster, 2006). Due to its agriculture-dominated socioeconomic infrastructure, India gives a high priority to the forecasting of the dry and wet spells in the monsoon season (Webster et al., 2010). During the monsoon season, evaporation over Arabian Sea and Indian Ocean provides the latent heat flux and produces a large quantity of precipitable water (Medina et al., 2010). This water invigorates the mesoscale convective systems, which under favorable meteorological condition may lead to cloudbursts.

The cloudburst analyzed in this study occurred over Uttarkashi $\left(30.73^{\circ} \mathrm{N}, 78.45^{\circ} \mathrm{E}\right)$, Uttarakhand, India, on 3 August 2012, during monsoon season. Uttarkashi is situated at the bank of river Bhagirathi and has an average elevation of $1165 \mathrm{~m}$. According to the 2001 census, Uttarkashi has an average population of 16220 (CCI, 2004). However, due to its religious importance, a large number of pilgrims were present around Uttarkashi when the cloudburst occurred. According to IMD, the monthly accumulated rainfall amounts during monsoon season of 2012 were $45.6 \mathrm{~mm}$ during June, $345.7 \mathrm{~mm}$ during July, $514.5 \mathrm{~mm}$ during August, and $133.5 \mathrm{~mm}$ during September (http://www.imd.gov.in/section/hydro/distrainfall/webrain/ uttarakhand/uttarkashi.txt). A major portion $(>100 \mathrm{~mm})$ of this rainfall occurred on 3 August 2012. The heavy rain produced during the cloudburst caused a heavy flash flood that disrupted life in Uttarkashi and neighboring areas like Ukhimath and Jakholi, and resulted in the death of about 120 people (http://chimalaya.org/2013/06/19/ disaster-in-uttarakhand-india-huge-death-toll/).

Figure 1 shows the input topography for simulation of the Uttarkashi cloudburst event. The three boxes are the three nested domains. The resolution of topography increases as we move towards the inner domains. The river Ganga flows close to Uttarkashi, and flows southeastward through the Indo-Gangetic Plain before flowing into the Bay of Bengal.

\section{Data sets used}

We used NCEP Global Final Analysis (NCEP et al., 2000) Final (FNL) reanalysis data to analyze the wind vector, temperature, relative humidity, and geopotential height at $500 \mathrm{hPa}$, observed over Northern India on 1, 2, and $3 \mathrm{Au}-$ gust 2012. Meteosat-7 satellite cloud distribution over monsoon Asia, on 1, 2, and 3 August 2012 at 06:00, 18:00, and 21:00 UTC was analyzed. Surface observations from AWSs and synoptic stations were used to analyze the spatial distribution of near-surface atmospheric fields. Vertical sounding data are used to analyze the vertical stability of the at-

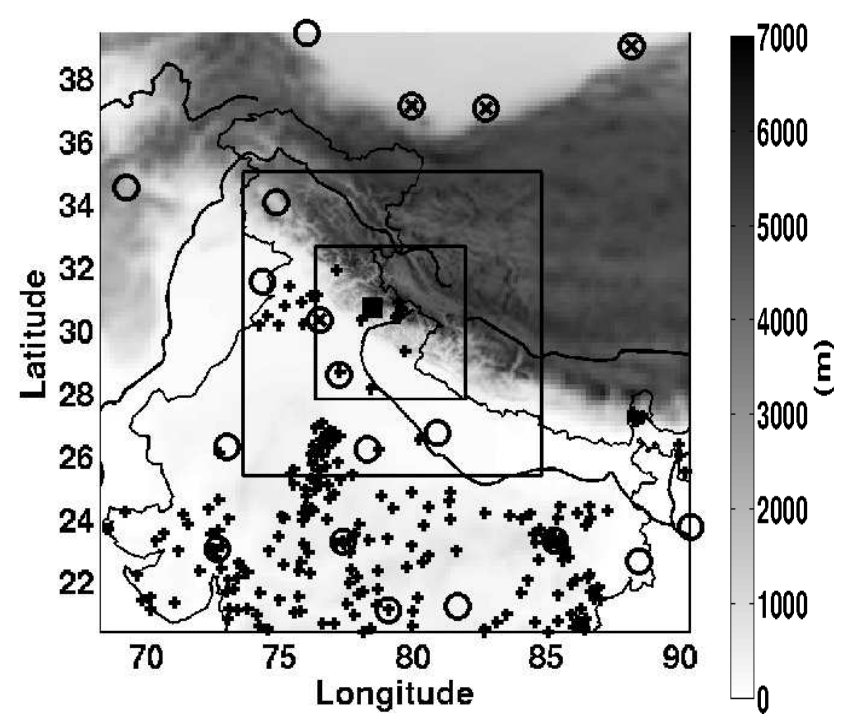

Figure 1. Terrain for simulation of the cloudburst over Uttarkashi. The three boxes are the three nested domains. Notice that the resolution of the topography increases towards the inner domain. The filled square denotes the location of where cloudburst had occurred, circles denote the location of the sounding stations, crosses denote the locations of the sounding stations for which the soundings are plotted, and plus symbols show the locations of the AWS stations against which the surface simulations are compared.

mosphere. Forty-eight-hour NOAA ARL HYSPLIT ${ }^{1}$ back trajectory was used to analyze the origin of the instabilities. The TRMM 3B42v7 daily data set was used to analyze the rainfall distribution on 3 August 2012. We also used TRMM $3 \mathrm{~B} 42 \mathrm{v} 73 \mathrm{~h}$ data to analyze the accuracy of the simulated precipitation.

\section{Results and discussion}

\subsection{Observation analysis}

\subsubsection{Analysis of reanalysis data}

Analysis of FNL data provides a description of spatiotemporal evolution of the synoptic-scale global atmosphere. Therefore, the atmosphere variables derived from the FNL data may shed some light on the processes involved in any atmospheric event. We looked into the wind vector, temperature, relative humidity, and geopotential height at $500 \mathrm{hPa}$ derived from the FNL in order to understand the propagation of the Uttarkashi cloudburst.

Figure 2 shows the wind vector, temperature, relative humidity, and geopotential height at $500 \mathrm{hPa}$, observed over Northern India on 1, 2, and 3 August 2012. On 1 August, the flow over Uttarkashi was predominantly northerly and

\footnotetext{
${ }^{1}$ See http://ready.arl.noaa.gov/HYSPLIT.php and http://ready. arl.noaa.gov
} 

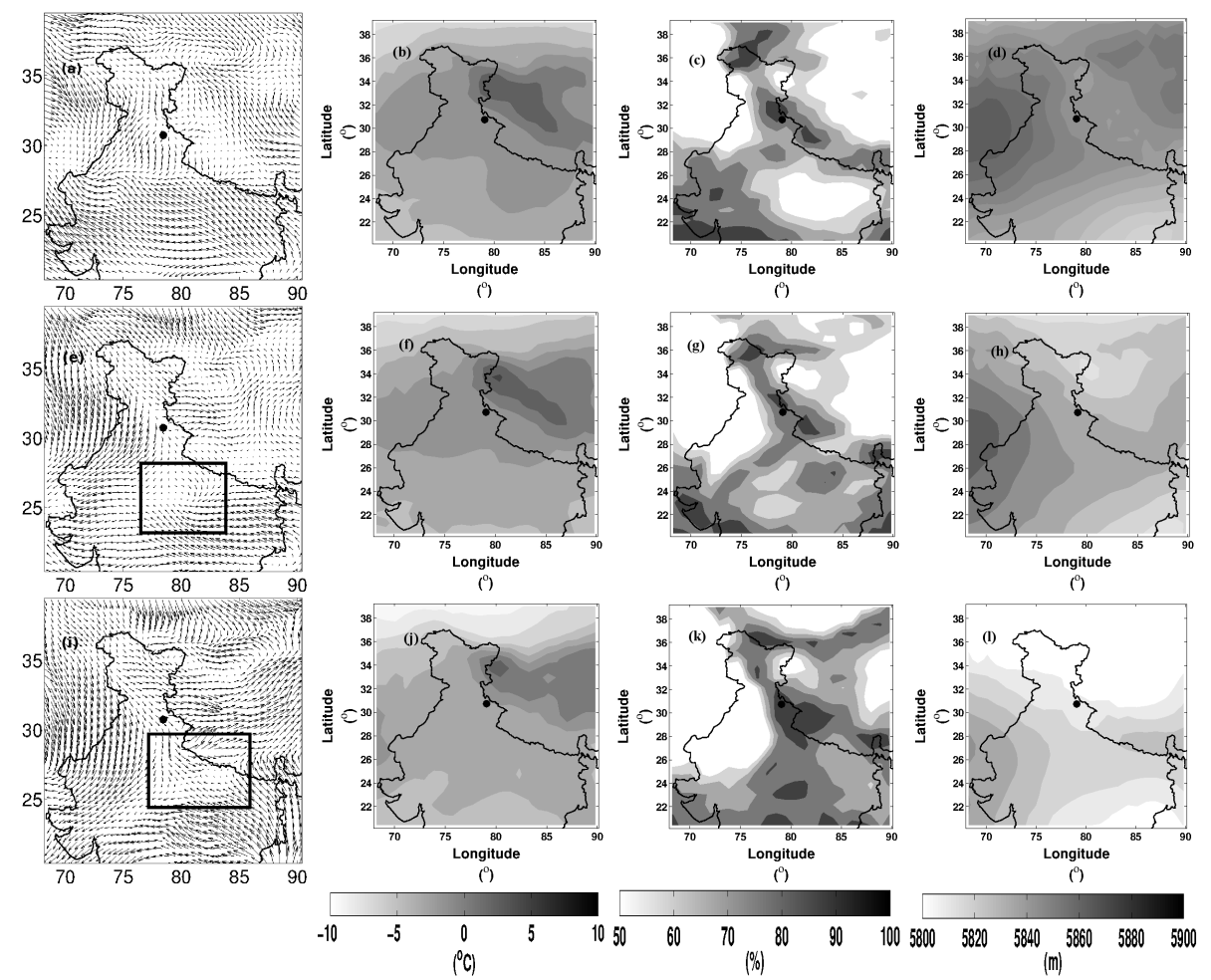

Figure 2. The diurnal average of atmospheric structure on $500 \mathrm{hPa}$ during 1, 2, and 3 August 2012. Panels (a), (e), and (i) show the wind vector (convergence and divergence zones are marked); (b), (f), and (j) show temperature; (c), (g), and (k) show the relative humidity; and (d), (h), and (l) show the geopotential height. Panels (a)-(d) are for 1 August, (e)-(h) are for 2 August, and (i)-(l) are for 3 August 2012.

northeasterly. However, over the state of Madhya Pradesh, far south of Uttarkashi, a south-southeasterly disturbance is noticeable. On 2 August, a convergence (Fig. 2e) started to form over the Indo-Gangetic Plain on the southeast of Uttarkashi. This convergence moved over Uttarkashi on $3 \mathrm{Au}-$ gust. A sharp divergence of flow (Fig. 2i) is observed along the foothills of Himalayas. Temperature maintained a sharp front over Uttarkashi for the entirety of 1,2, and 3 August, though on 3 August the sharpness had decreased after triggering of the event. The atmosphere to the north of Uttarkashi was relatively warmer. It is also seen that the atmospheric relative humidity maintained a sharp front over Uttarkashi for the entire period. The geopotential height showed a sudden decrease on 3 August compared to the previous 2 days, which indicates a dynamic low or pressure dropping. The summer convection over Madhya Pradesh and Tibetan Plateau provided the energy for instabilities over Uttarkashi, and the orographic lifting at Himalayan foothills and presence of transported moisture from the Bay of Bengal triggered the sudden condensation of the clouds.

Strong barotropic shear triggers the transient vortices and maintains them over the western Himalayan region during the monsoon onset (Krishnamurti et al., 1981). Also, regional circulations in the Himalayan region are affected by the surface heating of the Tibetan Plateau, and it becomes appar- ent during premonsoon and monsoon seasons (Yanai and $\mathrm{Li}$, 1994). Though the time of the cloudburst did not correspond to the monsoon onset, the easterly wind shear was still very strong. This shear also indicates that the mid-level cyclonic vortex of this storm is triggered and driven by the barotropic dynamics. The mid-level lows of these storms also enable strong moisture transfer to their eye.

Based on the analysis of synoptic-scale fields, and considering the meteorological conditions, we hypothesize the following dynamic mechanism of cloudbursts, which we confirm by observational and numerical evidence:

- The atmosphere should have adequate moisture to be able to build a favorable situation for a cloudburst. The presence of a monsoon trough over the Indian landmass during the month of August enables moisture from the Arabian Sea and the Bay of Bengal to travel deep into the Himalayan foothills, which fuels the cloudburst.

- Cloudburst occurs in a temperature and humidity front, i.e., when warm air meets cold air and saturated air meets unsaturated air. This front is dynamically favorable for cloudbursts. 

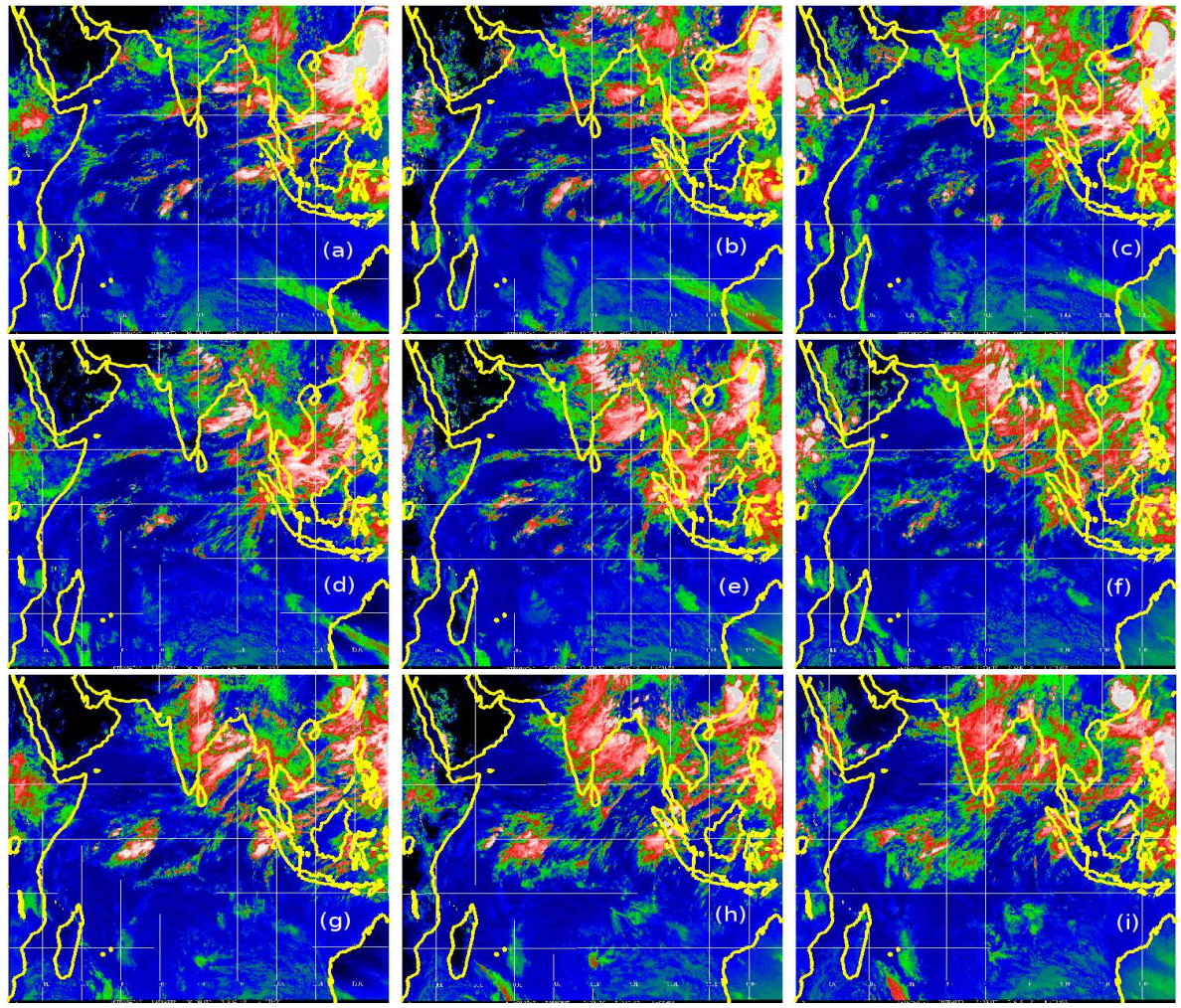

Figure 3. Meteosat-7 image of the clouds during 1 August (a, b, and c), 2 August (d, e, and f), and 3 August 2012 (g, h, and i) at 06:00, 12:00, and 18:00 UTC.

\subsubsection{Analysis of satellite images}

Meteosat-7 satellite images of clouds are useful to understand the propagation of convection in synoptic scale. Figure 3 shows the cloud distribution over monsoon-Asia on 1, 2, and 3 August 2012 at 06:00, 18:00, and 21:00 UTC. On 1 August, a convection center is observed at the extreme east of India, and over Myanmar. Strong diurnality was prominent from the cloud distribution around the convection center. On 2 August, the convection began to disperse and clouds slowly accumulated over the Indian landmass. On 3 August, the concentration of cloud over the Indian landmass peaked, indicating wide convection over central India, Madhya Pradesh, and adjacent regions. This widespread convection fueled the cloudburst storm, and the high concentration of clouds provided the optimal meteorological condition.

\subsubsection{Analysis of surface observations}

We use topography-dependent Delaunay triangulation $(\mathrm{Hu}$, 1995) to create the daily averaged gridded field using the available surface observations from AWS and synoptic stations. These maps help us in analyzing the spatial distribution of the atmospheric fields. The locations of the stations whose data are used in this study are shown in Fig. 1.
Figure $4 \mathrm{a}-\mathrm{f}$ show the surface distribution of the diurnal average temperature, relative humidity, rainfall intensity, pressure, wind speed, and wind direction on 3 August 2012. Diurnal variation in the meteorological variable observed at an AWS, situated at Dehradun $\left(30.34^{\circ} \mathrm{N}, 78.04^{\circ} \mathrm{E}\right)$, is shown in the inset. It is seen that the temperature in the north and east of Uttarkashi was lower than that in the south and west. AWS-recorded temperature at Dehradun shows a sharp drop of $5^{\circ} \mathrm{C}$ at 10:00 UTC, due to the passing of the convection eye. Interestingly, a sharp front over Uttarkashi may be noticed in the relative humidity plot. Air in the south and west of Uttarkashi has a relative humidity level of around $90 \%$, and in the north and east it is around $70 \%$. This observation supports the hypothesis that a moisture front is needed in the formation of cloudburst. Over Dehradun, air became more humid from 10:00 UTC because of the precipitation event at that time. Again, the sparseness of data prevented us from analyzing the variation of the spatial pressure fields. However, the pressure fields show the expected regional variation with higher pressure at the low-altitude southern part of the domain and lower pressure at the high-altitude northern part. A slight drop in surface pressure $(\sim 3 \mathrm{hPa})$ around 10:00 UTC may be noticed. Since the cloudburst is a highly localized event, the surface distribution of rainfall is not able to capture the event well. However, the station at the Dehradun shows three distinct rainfall events, with the first small one 

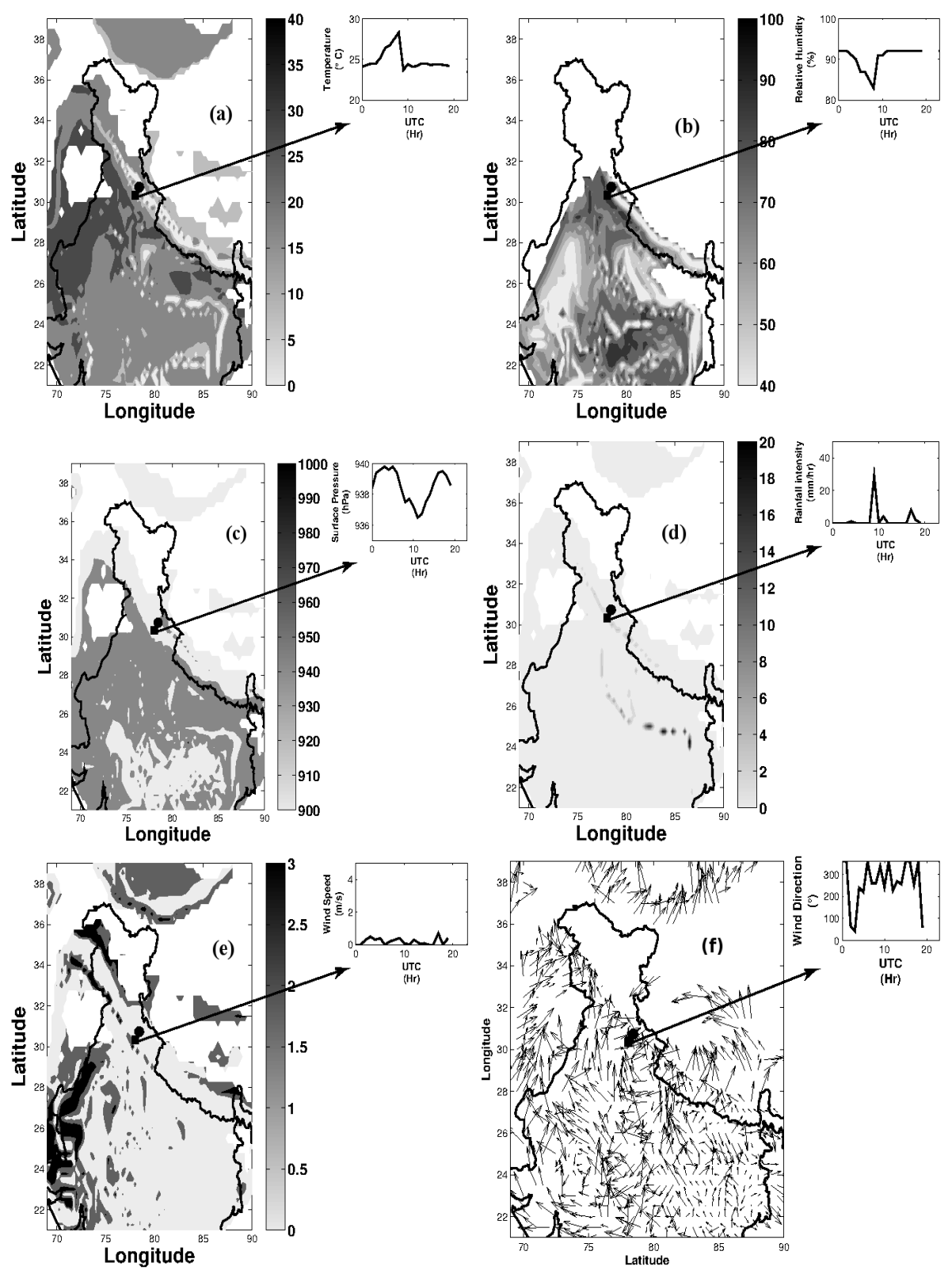

Figure 4. Plots of automatic weather station fields: (a) temperature, (b) relative humidity, (c) pressure, (d) rainfall intensity, (e) wind speed, and (f) wind direction surface distribution for an automatic weather station located at Dehradun $\left(30.34^{\circ} \mathrm{N}, 78.04^{\circ} \mathrm{E}\right)$ for 3 August 2012 . The location of Dehradun is shown by a black square in the map.

from around 05:00 UTC, the second large one from 8:00 to 12:00 UTC, and the third intermediate one from 16:00 to 20:00 UTC. A peak rainfall of $25 \mathrm{~mm} \mathrm{~h}^{-1}$ was indicative of a cloudburst-like system. Wind speed shows very little variation in space and time. Wind speed was higher over the western part of the domain, and it facilitated the moisture transport from Arabian Sea. Wind speed over the Dehradun showed no diurnal variation, and was of very low magnitude $\left(\sim 1 \mathrm{~m} \mathrm{~s}^{-1}\right)$. Wind in the northeast of Uttarkashi was northerly dominated and over the south of Uttarkashi the wind was southerly dominated, indicating the presence of a convective system over Uttarkashi. The west of Uttarkashi was southwesterly dominated, which transported the moisture from the Arabian Sea to the system. In the southeast of Uttarkashi, the winds were southeasterly, which transported the moisture from the Bay of Bengal to the cloudburst system.

\subsubsection{Vertical sounding analysis}

The sounding plot in Fig. 5a indicates that, on $2 \mathrm{Au}-$ gust 2012, the entire atmosphere was highly unstable, with 


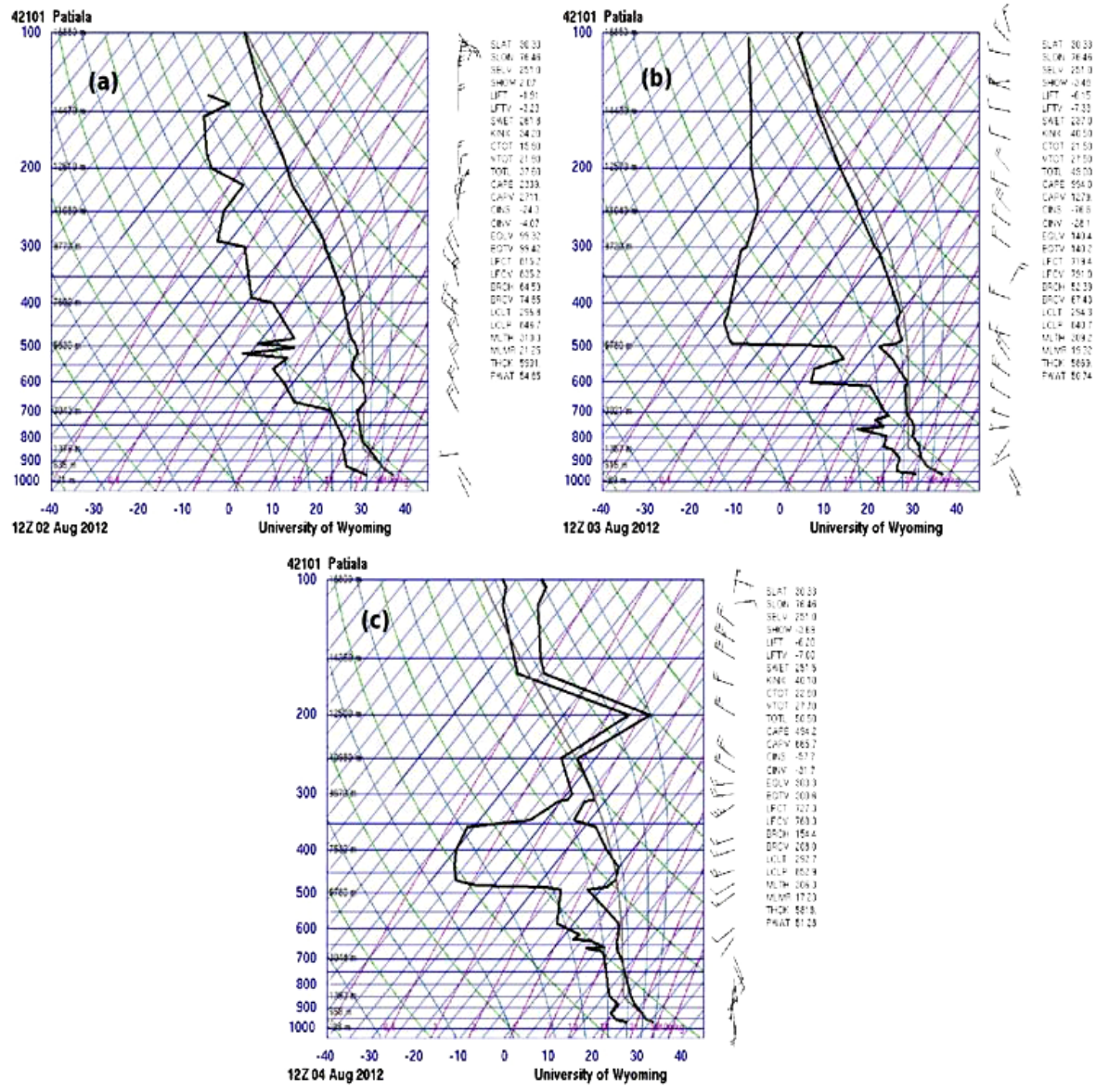

Figure 5. Radiosonde data taken at 12:00 UTC on (a) 2 August, (b) 3 August, and (c) 4 August 2012 over Patiala $\left(30.34^{\circ}\right.$ N, $76.38^{\circ}$ E) near Uttarkashi $\left(30.73^{\circ} \mathrm{N}, 78.45^{\circ} \mathrm{E}\right)$, plotted on a skew-T graph.

very high convective available potential energy (CAPE) (2399 $\mathrm{J} \mathrm{kg}^{-1}$ ). In Fig. 5b, during 3 August 2012, the CAPE (convective available potential energy) magnitude declined ( $994 \mathrm{~J} \mathrm{~kg}^{-1}$ ), possibly fueling the storm, and a shallow cloud layer formed, indicated by a sudden drop in dew-point temperature at $500 \mathrm{hPa}$. In Fig. 5c, during 4 August 2012, after the cloudburst took place, CAPE further reduced to a value of $494.2 \mathrm{~J} \mathrm{~kg}^{-1}$ and the cloud base moved to a height $200 \mathrm{hPa}$, indicated by the close separation of temperature and dewpoint temperature at that height. During all these days the convective inhibition $(\mathrm{CIN})$ remained very low $\left(<0 \mathrm{~J} \mathrm{~kg}^{-1}\right)$, indicating favorable conditions for a storm.

\subsubsection{Precipitation}

Figure 6a shows the daily accumulated TRMM 3B42v7 precipitation on 3 August 2012 centered over Uttarkashi. The Uttarkashi rainfall was about $100 \mathrm{~mm}$ on 3 August 2012. The rainfall patch to the south of Uttarkashi indicates the instabilities starting from Madhya Pradesh, and that over Tibetan Plateau indicates the instabilities at that location. These two instabilities interacted with each other and, under orographic forcing and optimal cloud cover over Uttarkashi, caused the cloudburst.

Browning (1979) examined the precipitation efficiency of orographic clouds. The study site was low hills over the British Isles. It was shown that high efficiency was a result of efficient natural seeding and a synoptic-scale initial saturated flow. In the cloudburst system, such a favorable situation leads to a higher efficiency for precipitation. Elliott and Shaffer (1962) showed that the deeper vertical penetration of the convective elements can compensate for the water loss by entrainment, resulting in a greater condensate and precipitation production. In our study, the entrainment generated by the mixing of wet and dry wind caused a lowering of water vapor concentration. However, the orographic uplifting of the convective core compensated for it and resulted in cloudburst. In their simulation Krishbaum and Durran (2004) found that wider mountains favor embedded convection compared to the narrow ridges. As the Himalayas are rather wide, they do favor the embedded convection, which is the heart of any cloudburst system. 


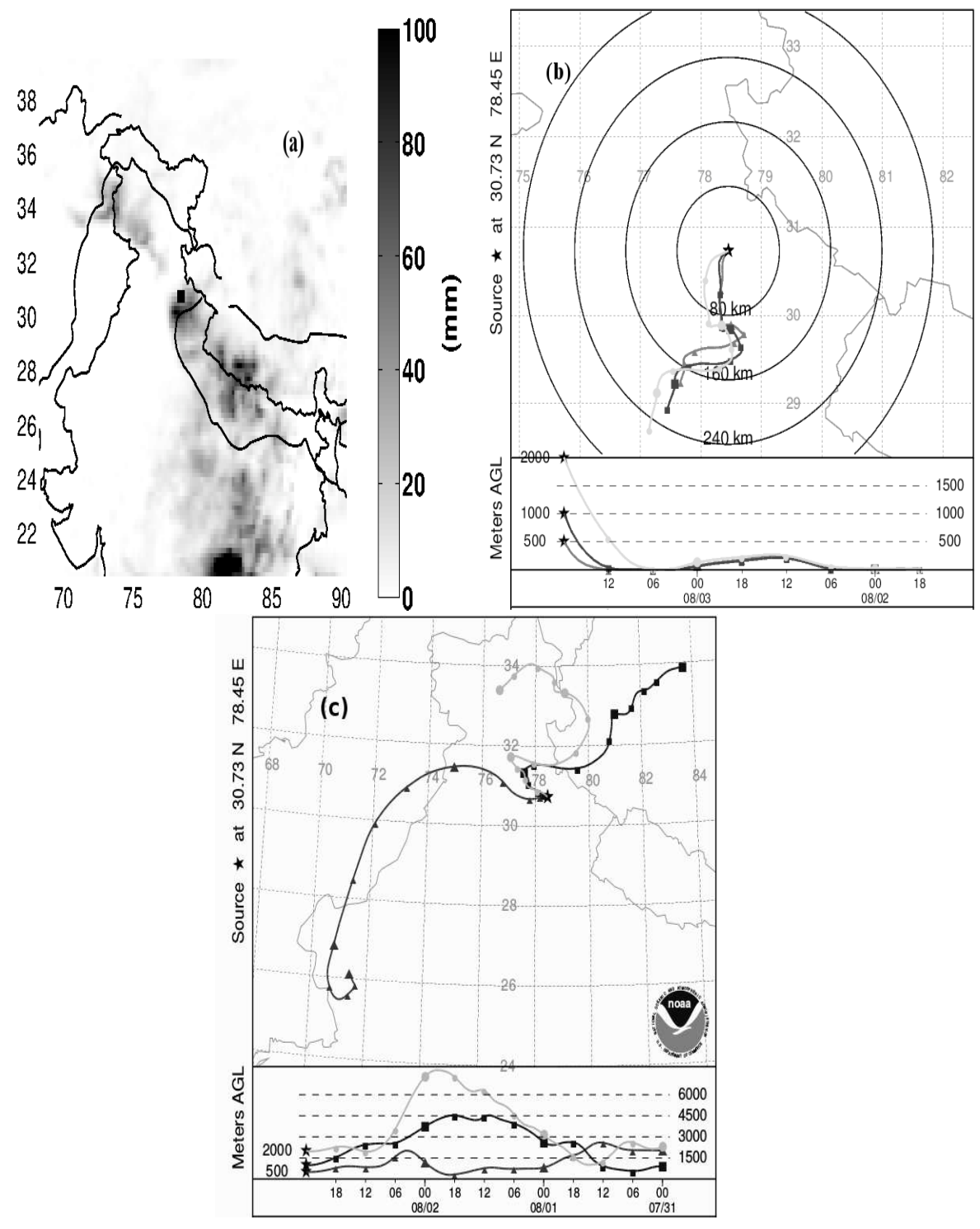

Figure 6. (a) TRMM 3B42v7 daily accumulated rainfall for 3 August 2012, (b) $48 \mathrm{~h}$ back trajectories towards Uttarkashi ending 18:00 UTC on 3 August 2012, and (c) $96 \mathrm{~h}$ back trajectories towards Uttarkashi ending 00:00 UTC on 3 August 2012.

\subsubsection{Back trajectory analysis}

Back trajectories enable us to identify the location of convection source. We used NOAA ARL HYSPLIT model to locate the origin of convection which resulted in cloudburst. Forty-eight-hour back trajectories ending in Uttarkashi at 18:00 UTC on 3 August (Fig. 6b) show that, at $2 \mathrm{~km}$ above ground level, the environment over Uttarkashi was dominated by the convected surface air starting from Madhya Pradesh, and it interacted with the westerlies at the lower level $(500 \mathrm{~m}-1 \mathrm{~km})$. The presence of a mid-level low over Uttarkashi is clear in the trajectories as the air parcels moved from surface level to the height of $500 \mathrm{~m}-2 \mathrm{~km}$ over Uttarkashi. Considering the amount of moisture available, we can say that the moisture came from the Bay of Bengal and Arabian Sea, the two prominent moisture sources for India. Figure $6 \mathrm{c}$ shows the $96 \mathrm{~h}$ back trajectories ending on Uttarkashi at 00:00 UTC on 3 August. It gives an indication of moisture and convection movement from the coast of Arabian Sea, the Tibetan Plateau, and the Kashmir region of north India.

\subsection{Numerical analysis}

\subsubsection{Model description and experiment setup}

The WRF model with the Advanced Research WRF (ARW) dynamic core version 3.4 is used as the regional climate model in this study. WRF is a next-generation mesoscale 
modeling system which is designed for both operational forecast and to serve as a platform for atmospheric research.

Our modeling strategy is broadly divided into three stages. First, we evaluate the ability of numerical model to simulate the cloudburst event over the region of interest in a basic (control) configuration. Next, we perform a series of numerical experiments, using different schemes in the suite of physical parameterizations, model vertical levels, and spinup time, in order to identify the configuration of the model (at $18 \mathrm{~km}$ resolution) which best simulates the near-surface atmospheric observations during the cloudburst event. We conclude our study with high-resolution nested numerical simulations using the best configuration $(18,6$, and $2 \mathrm{~km})$ over selected region.

The initial and boundary conditions (ICs, BCs) for the large-scale atmospheric fields, and the initial conditions for different soil fields (e.g., moisture content, soil layer temperature) were interpolated from the $1^{\circ} \times 1^{\circ}$ NCEP Global Final Analysis (FNL) using the WRF Preprocessing System (WPS). The boundary conditions for the model simulations were created from temporal interpolation of the $6 \mathrm{~h}$ FNL data. The momentum budget at subgrid scale in NWP can be erroneous due to a missing subgrid-scale drag term in the momentum equation of the model. This can be significant when the domain has large variations in topography. To overcome this problem, we used gravity wave drag as a momentum-damping mechanism. The model vertical atmospheric structure strongly depends on the initialization of surface fields and model spin-up time (Wang et al., 2012). As mesoscale convective systems evolve due to specific vertical atmospheric structure, we performed sensitivity analysis of the spin-up time to properly calibrate the model.

The initialization of the models was done using the 00:00 UTC reanalysis field of 2 August 2012. The simulation was carried out for a $48 \mathrm{~h}$ period - 00:00 UTC on 2 August to 00:00 UTC on 4 August 2012. The first $24 \mathrm{~h}$ were taken as the spin-up time of the model. Therefore, the results are valid from 00:00 UTC on 3 August 2012 to 00:00 UTC on $4 \mathrm{Au}-$ gust 2012. Table 1 gives the model configuration used for these simulations, and Table 2 shows the physics and model options used for the control simulation.

To investigate the sensitivity of different model configurations and find the suite of parameterizations and model options that best simulate the near-surface atmospheric fields (temperature, relative humidity, pressure, and rainfall intensity), we changed the model physics (microphysics, cumulus, land surface, long- and shortwave radiation, and planetary boundary layer) and options (vertical level and spin-up time) one at a time, keeping the other options the same as in the control experiment. We evaluated the performance of different sensitivity experiments and the best options are used in the high-resolution nested experiment. The use of best options ensures improved quality of boundary conditions for the inner nests.
Table 1. Different model configuration options used in the control as well as sensitivity experiments.

\begin{tabular}{ll}
\hline Options & Specifications \\
\hline Domain center & Uttarkashi $\left(30.73^{\circ} \mathrm{N}, 78.45^{\circ} \mathrm{E}\right)$ \\
Resolution & $18 \mathrm{~km}$ \\
Time step & $9 \mathrm{~s}$ \\
Grid dimension & $120 \times 120$ \\
Model static fields & USGS \\
IC and BC & Final reanalysis (FNL) \\
Gravity wave drag & Yes \\
\hline
\end{tabular}

Table 2. Different physics and model options used in the control experiments.

\begin{tabular}{ll}
\hline Options & Name/value \\
\hline Microphysics & Lin \\
Longwave radiation & RRTM \\
Shortwave radiation & Dudhia \\
PBL and surface physics & MYJ \\
Land surface model & Noah \\
Cumulus parameterizations & KeinFeitsh \\
Vertical levels & 45 \\
Spin-up time & $24 \mathrm{~h}$ \\
\hline
\end{tabular}

The high-resolution experiment involves three two-way nested domains centered at Uttarkashi. The outermost domain has a resolution of $18 \mathrm{~km}$ and dimension of $120 \times 120$ grid points, the intermediate domain has a resolution of $6 \mathrm{~km}$ and dimension of $181 \times 181$ grid points, and the innermost domain has a resolution of $2 \mathrm{~km}$ and dimension of $271 \times 271$ grid points. Assuming that the cloud system that caused the cloudburst can be resolved by the innermost domain with $2 \mathrm{~km}$ resolution, the convective parameterization was not used. This also ensures that our analysis of the cloudburst process will not be affected by any artifact of the convective parameterization.

\subsubsection{Sensitivity study}

In order to arrive at the best parameterization, we combined the prediction errors for temperature, relative humidity, surface pressure, and rainfall intensity into a single index, termed the performance metric (PM). Hourly AWS observations were used for calibration of WRF, and all the variables were given equal importance in the performance index. The $\mathrm{PM}$ is defined as

$\mathrm{PM}_{\mathrm{p}}=\frac{1}{N_{\mathrm{v}}} \sum_{v} \frac{e_{\mathrm{pv}}-\inf _{\mathrm{p}} e_{\mathrm{pv}}}{\sup _{\mathrm{p}} e_{\mathrm{pv}}-\inf _{\mathrm{p}} e_{\mathrm{pv}}}$,

where $\mathrm{PM}_{\mathrm{p}}$ is performance metric for parametrization, $N_{\mathrm{v}}$ is the number of variable types (four for the present case), $e_{\mathrm{pv}}$ is the mean absolute relative error (MARE) of each variable and parameterization options calculated for all the time 
Table 3. The performances of different options in WRF simulation for Uttarkashi cloudburst.

\begin{tabular}{|c|c|c|c|c|c|c|c|}
\hline \multirow{3}{*}{$\begin{array}{l}\text { Sensitivity type } \\
\text { Cumulus }\end{array}$} & \multicolumn{7}{|c|}{ Options and performance metric } \\
\hline & $\mathrm{KF}$ & BMJ & CAM & GRELL & TIEDKE & & \\
\hline & 0.08 & 0.63 & 0.33 & 0.38 & 0.50 & & \\
\hline \multirow{2}{*}{ Land surface } & NOAH & RUC & & & & & \\
\hline & 0.67 & 0.33 & & & & & \\
\hline \multirow[t]{2}{*}{ Longwave } & RRTM & GODDARD & RRTMG & & & & \\
\hline & 0.50 & 0.50 & 0.63 & & & & \\
\hline \multirow[t]{2}{*}{ Shortwave } & DUDHIA & GODDARD & RRTMG & & & & \\
\hline & 0.33 & 0.67 & 0.57 & & & & \\
\hline \multirow[t]{2}{*}{ Microphysics } & LIN & GODDARD & MILBRANDT & MORRISON & THOMPSON & WDM & WSM \\
\hline & 0.33 & 0.47 & 0.40 & 0.30 & 0.67 & 0.37 & 0.53 \\
\hline \multirow[t]{2}{*}{ PBL } & MYJ & MYNN & QNSE & & & & \\
\hline & 0.10 & 0.50 & 0.75 & & & & \\
\hline \multirow[t]{2}{*}{ Vertical level } & NORMAL & HIGH & LOW & & & & \\
\hline & 0.50 & 0.50 & 0.63 & & & & \\
\hline \multirow[t]{2}{*}{ Spin-up } & 1 day & 5 days & & & & & \\
\hline & 0.00 & 1.00 & & & & & \\
\hline
\end{tabular}
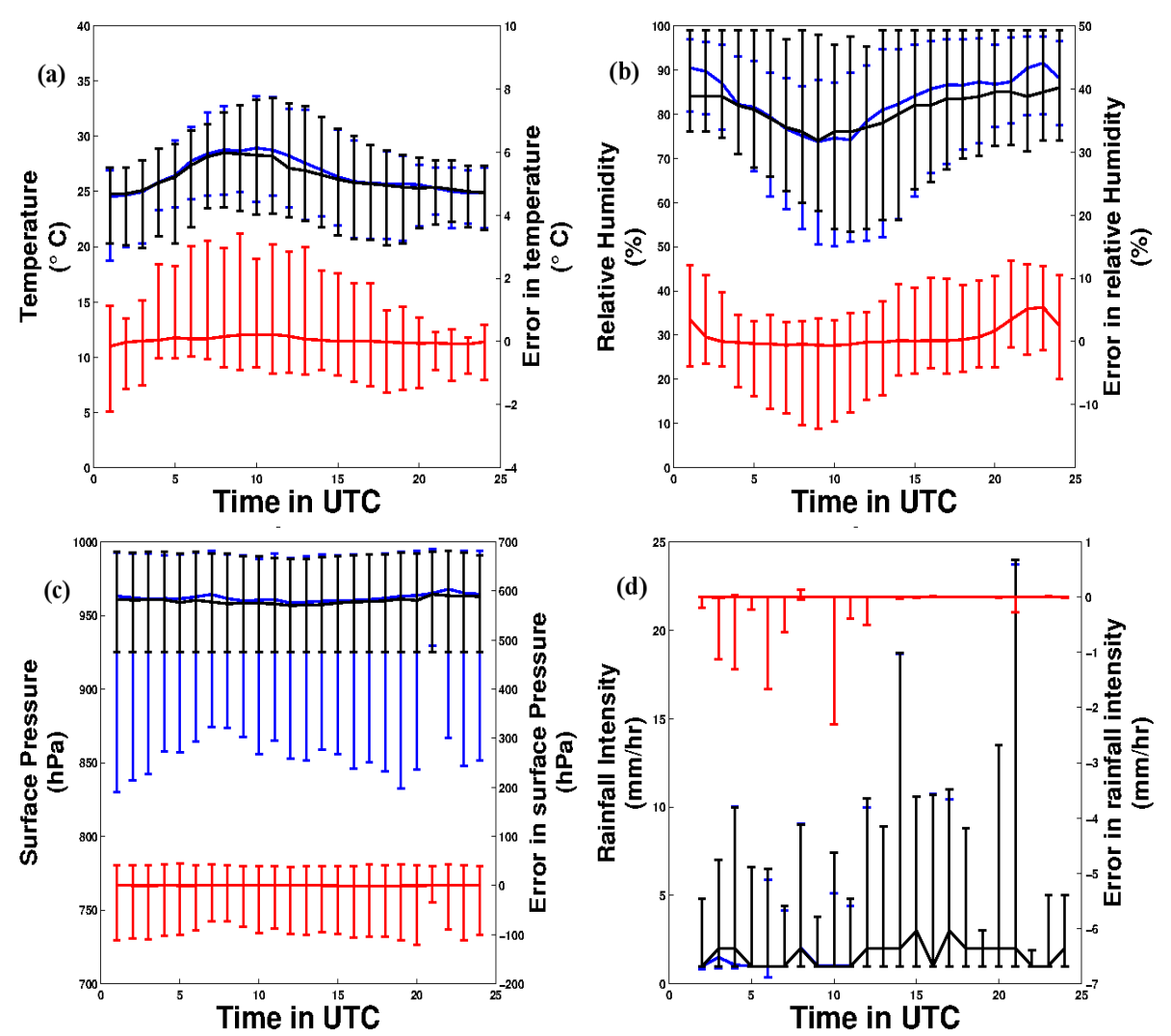

Figure 7. Comparison of automatic weather station fields and WRF-simulated temperature, relative humidity, pressure, and rainfall intensity, using the best configuration for 3 August 2012. The black line denotes the observation, the blue line denotes the simulated value, and the red line denotes the error between them. The solid lines are corresponding 0.5 quantiles, and spreads are 0.1 and 0.9 quantiles of the geographical distributions. 


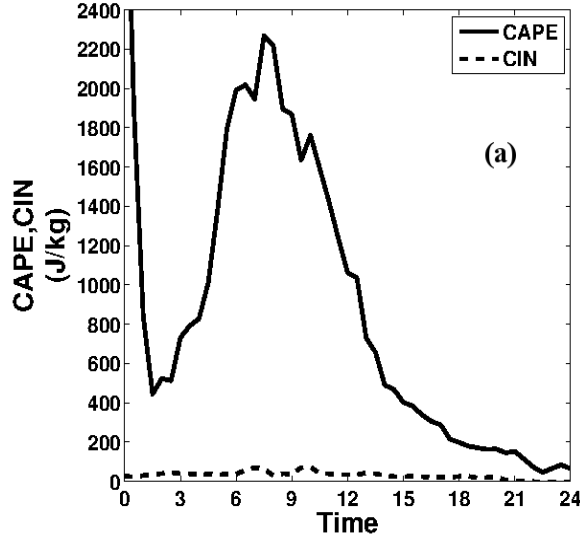

(hr)
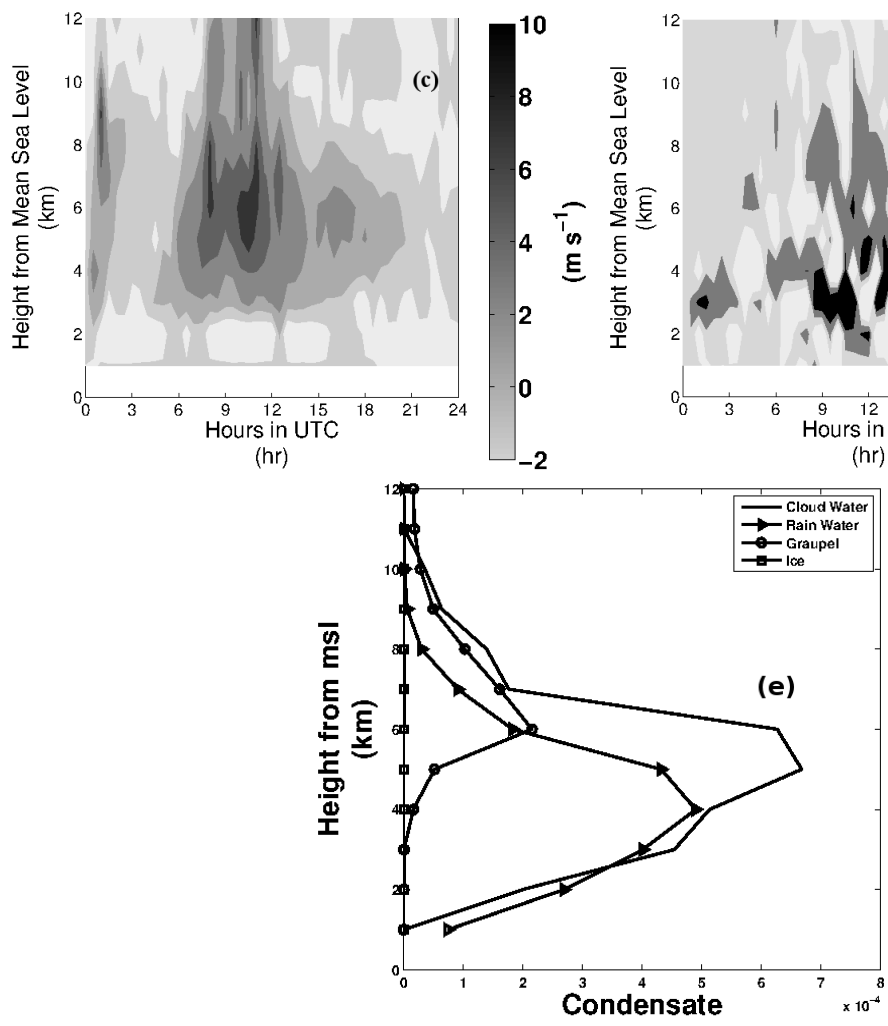

$(\mathrm{kg} / \mathrm{kg})$

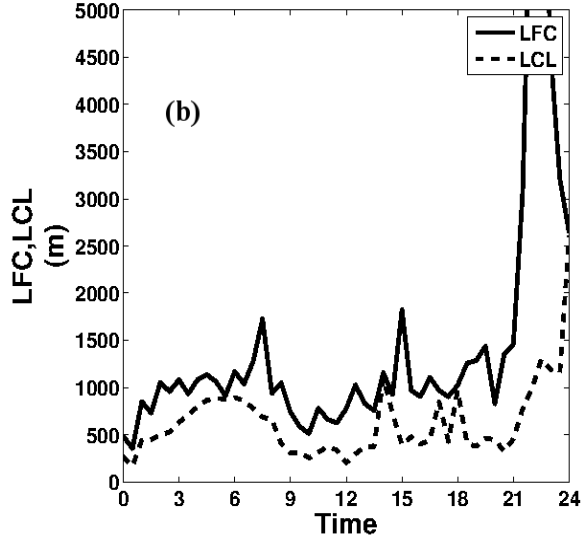

(hr)

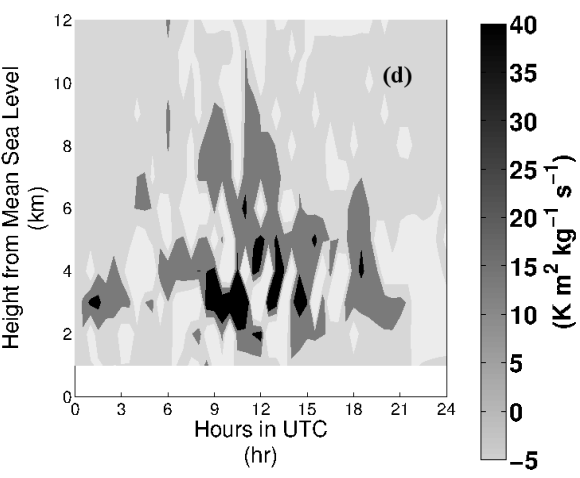




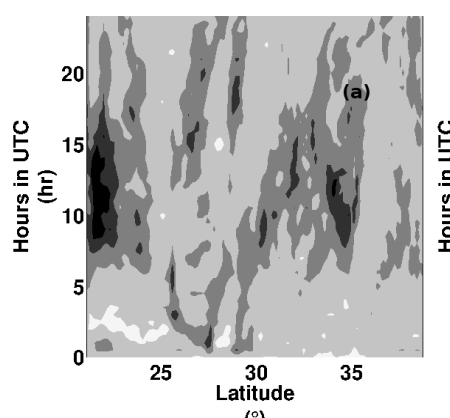

$\left({ }^{\circ}\right)$

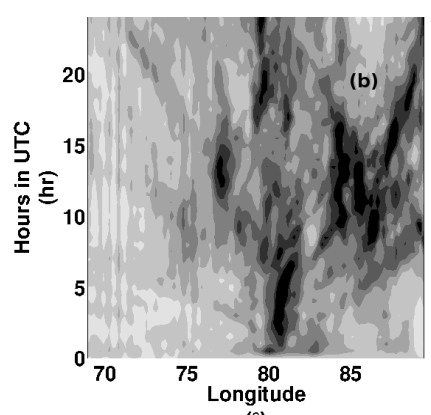

$\left({ }^{\circ}\right)$

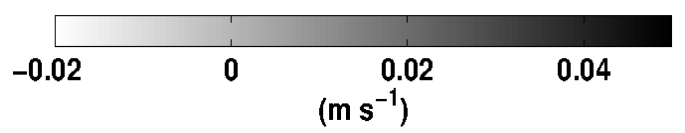

Figure 9. Model-simulated (a) longitudinally averaged vertical velocity, and (b) latitudinally averaged vertical velocity for Uttarkashi during 3 August 2012.

tion which determine the configuration of the high-resolution experiments. Although a detailed discussion of these sensitivities is beyond the scope of this paper, a few points may be noted.

- In microphysical parameterization, the two best options (GODDARD and Morrison) have double-moment formulation with six microphysical classes.

- Vertical level sensitivity shows that having too many vertical levels may not be a good option if simulation of near-surface fields is the only concern. However, as we are interested in altitude-dependent cloud processes, it is desirable to have large number of vertical levels at that height. Therefore, despite the fact that having more vertical levels does not lead to improvement in results for simulating near-surface fields, we chose that option.

- Spin-up time sensitivities show that, as the difference between initialization time and the time of interest increases, the simulation of near-surface fields deteriorates. Since the study of the cloudburst event is an initial-value problem, the prediction quality deteriorates as we move further into the past from the event of interest to initialize our model. This is due to the fact that only updating boundary conditions cannot provide the sufficient information to generate the regional pattern of different meteorological variables, and the errors in simulation continue to increase as the integration advances.

Near-surface atmospheric fields like temperature, relative humidity, surface pressure, and rainfall intensity from the best configuration simulation of the Uttarkashi cloudburst are compared against the hourly observations from AWSs during 3 August 2012. Figure 7 shows the simulated and observed values as well as the difference between them. Simulated temperature, relative humidity, surface pressure, and rainfall match well with the AWS observation, and show no bias in the median values.

\subsubsection{Convective conditions}

Deep, moist convection like cloudbursts form by a two-stage mechanism: conditional instabilities and a trigger mechanism. Conditional instabilities are the state of ambient atmosphere in which the storm forms. The trigger mechanism is the external influence on the atmosphere which initiates the storm. Further instabilities that are needed to maintain the storm evolve in the storm process itself.

Figure 8a shows the time series of the maximum CAPE and maximum CIN observed over Uttarkashi. The CAPE started to increase around 02:00 UTC, achieved its peak value of $2200 \mathrm{~J} \mathrm{~kg}^{-1}$ around 09:00 UTC, and after that it dissipated until 21:00 UTC, when it became nearly zero. It is clear from the plot that the atmosphere over Uttarkashi during 3 August 2012 was very unstable, and the dominating CAPE fueled the storm. The high value of CAPE $\left(>1000 \mathrm{~J} \mathrm{~kg}^{-1}\right.$ ) signifies the fact that CAPE was one of the most important factors in triggering the cloudburst. For Uttarkashi cloudburst, CIN had a peak magnitude of around $45 \mathrm{~J} \mathrm{~kg}^{-1}$. The low value of CIN made the atmosphere favorable for convective storm throughout the day.

Figure $8 \mathrm{~b}$ shows the time series of the lifted condensation level (LCL) and the level of free convection (LFC) observed over Uttarkashi. LCL remained less than $1 \mathrm{~km}$ throughout 3 August 2012, and at around 21:00 UTC it started to recover and reached a height of $2.6 \mathrm{~km}$. LFC was also around 1 to $2 \mathrm{~km}$ during this day. These low heights of LCL and LFC indicate the presence of cloud and unstable atmosphere at very low altitude in the atmosphere, which favored the cloudburst.

Figure $8 \mathrm{c}$ shows the updraft profile over Uttarkashi simulated by WRF. The model simulates an updraft event at $4 \mathrm{~km}$ height from mean sea level, between 06:00 and 18:00 UTC, indicating major convective activity at that height throughout the day. Downdrafts at ground level occurred during the entire day, implying a condition favorable for severe thunderstorms.

The thermal and dynamical properties of the atmosphere can be analyzed by looking into the potential vorticity (PV) field. Hoskins et al. (1985) explained the application of PV in diagnostic study, weather analysis, and prediction. Wu (1995) pointed out a strong correlation of PV with the formation and development of rainstorms. The PV consists of three terms: relative vorticity, planetary vorticity, and stretching vorticity. Precipitation processes are primarily triggered by condensation latent heat release. PV is positively correlated with the moist adiabatic stability of the atmosphere and its vortex. Therefore, the vertical motions and stability of the atmosphere can be analyzed using PV. Figure 8d shows the PV over Uttarkashi for our study. The atmosphere near ground level, and at a height $2-10 \mathrm{~km}$ above mean sea level, was unstable during the entire day. This instability started to 

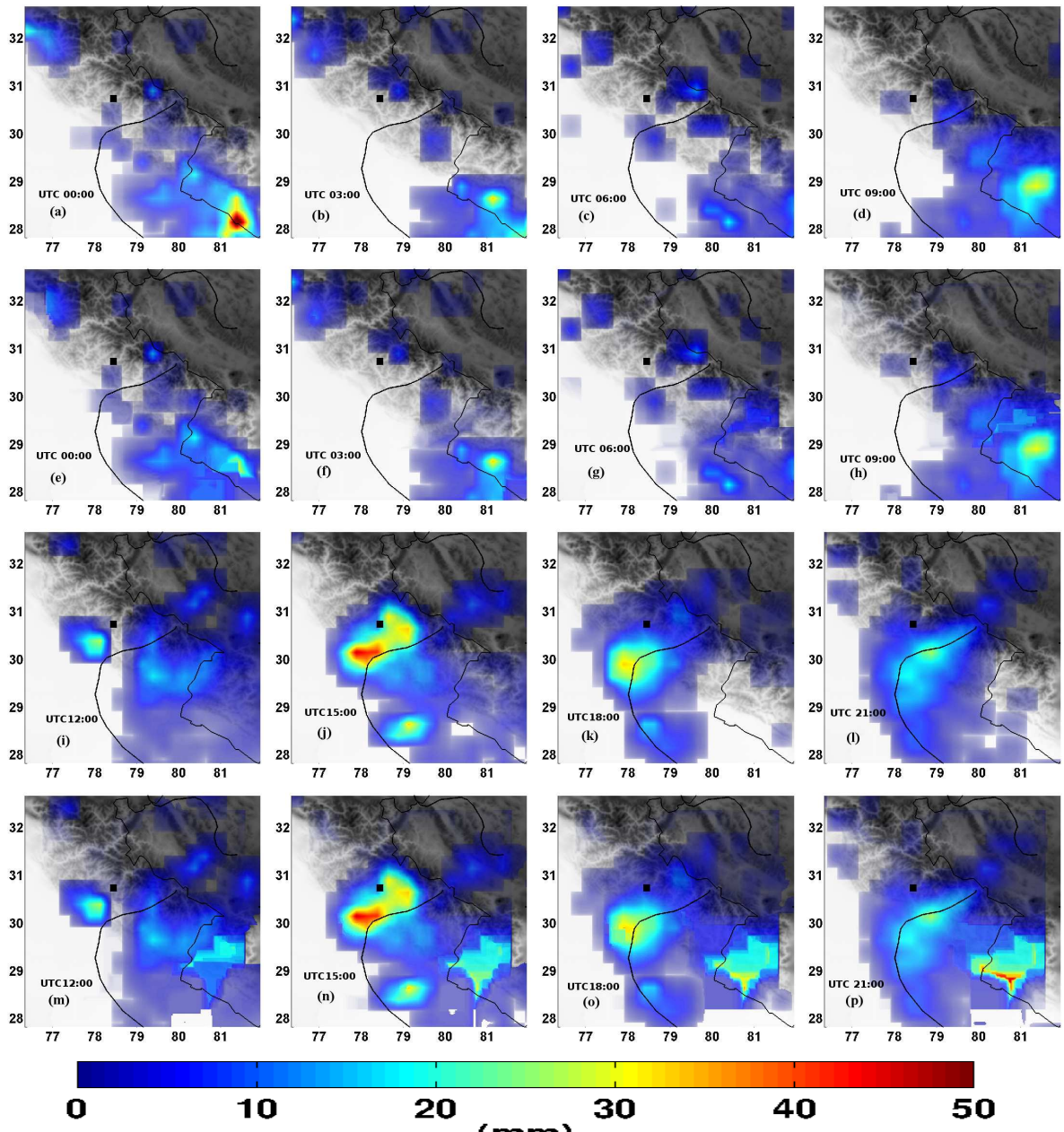

Figure 10. Comparison of TRMM 3B42v7 $3 \mathrm{~h}$ rainfall (a-d and $\mathbf{i}-\mathbf{l})$ and WRF simulation using the best nested configuration (e-h and $\mathbf{m}-\mathbf{p})$ for 3 August 2012 inside domain 3. The topography of the location is shown in grayscale in the background.

intensify and spread through the atmosphere up to a height of $10 \mathrm{~km}$ at 12:00 UTC. The instabilities dissipated at around 21:00 UTC. The vigorous activity of PV during the cloudburst indicates that it played a major role in the process of this storm.

Figure 8e shows the vertical distribution of different condensates, averaged for the innermost domain, in the case of the Uttarkashi cloudburst. Note that the region up to $6 \mathrm{~km}$ above mean sea level was dominated by rainwater, indicating heavy rains. The atmosphere up to $10 \mathrm{~km}$ was dominated by cloud water, which indicates deep cloud. Hardly any ice crystals were present in the atmosphere or in the cloud. The cloud was dominated by graupel. However, there are no hydrometry data against which these simulations could be validated. We can still hypothesize that the dominating graupel, in the presence of strong updraft, can generate charges to form thunderclouds. This formation of thunderclouds can enhance the possibility of cloudburst.
Figure $9 \mathrm{a}$ and $\mathrm{b}$ show the latitudinal and longitudinal propagation of the convection within the outermost domain for the Uttarkashi cloudburst. In the latitude-time plot, we can see the presence of two convection cores during 5:0015:00 UTC. One is around $35^{\circ} \mathrm{N}$ and the other is around $20^{\circ} \mathrm{N}$. Though there is no indication of clear movement of convections along latitude, these may have facilitated the convections at $30^{\circ} \mathrm{N}$ latitude which were active during 00:00-5:00 UTC and 15:00-23:00 UTC. This $30^{\circ} \mathrm{N}$ band convection was responsible for cloudburst over Uttarkashi $\left(30.73^{\circ} \mathrm{N}\right)$. In the longitude-time plot, we can see that the convection initiated from $80^{\circ} \mathrm{E}$ longitude and then propagated in two directions: one towards east, which spread over the entire band of longitude from 80 to $85^{\circ} \mathrm{E}$ during 10:0020:00 UTC, and the other towards west, which was active around $78^{\circ}$ E longitude during 10:00-15:00 UTC. The latter caused the Uttarkashi $\left(78.45^{\circ} \mathrm{E}\right)$ cloudburst. Convection over $80^{\circ} \mathrm{E}$ again became active during 15:00 UTC and lasted throughout the rest of the day. Though these simulations do 


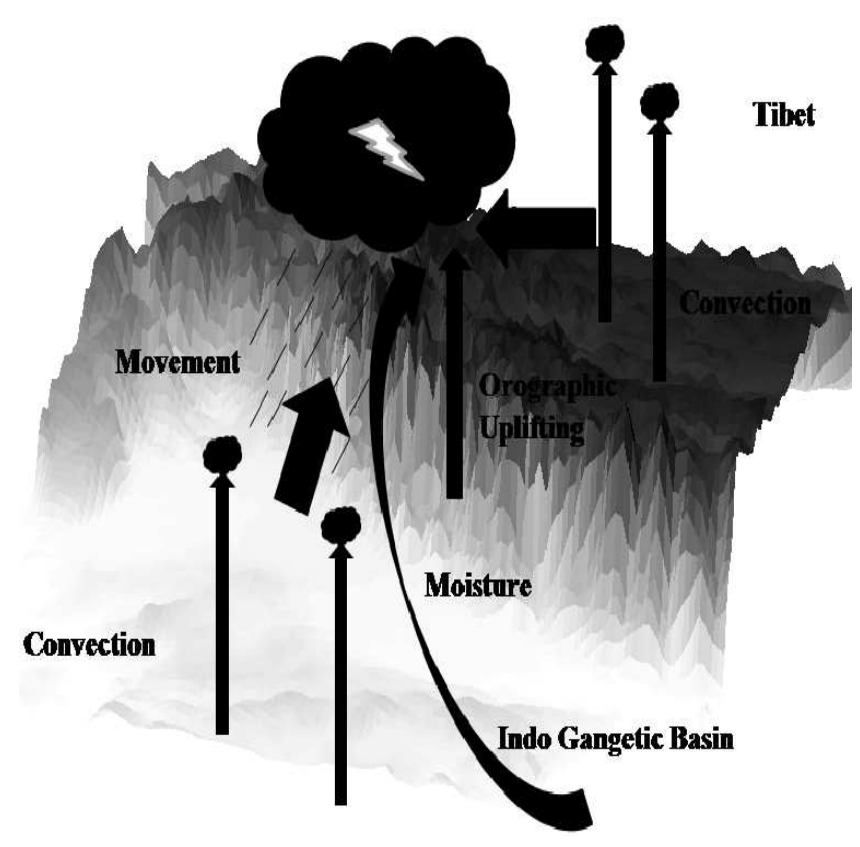

Figure 11. Conceptual model of the key meteorological elements that led to the cloudburst over Uttarkashi on 3 August 2012.

not entirely support our hypothesis of the origin of the convections over Madhya Pradesh and Tibet and their consequent interaction to burst the cloud, they do indicate that the convection over these two places could have played a major role in the cloudburst process.

\subsubsection{Results of precipitation simulations}

We compared the simulated $3 \mathrm{~h}$ accumulated rainfall $(2 \mathrm{~km} \times 2 \mathrm{~km})$ with the TRMM $3 \mathrm{~B} 42 \mathrm{v} 7$ rainfall $\left(0.25^{\circ} \times 0.25^{\circ}\right)$. We used a spatial window of $50 \mathrm{~km}$ to compare the TRMM observation values at any point with the simulated precipitation magnitude, and chose the closest magnitude as corresponding simulated precipitation at that grid point. We bilinearly interpolated the TRMM data to the model grid and searched for the closest precipitation magnitude for each grid point.

Figure 10 shows the comparison of simulated precipitation of innermost domain with the TRMM $3 \mathrm{~h}$ accumulated precipitation estimate for 8 synoptic hours, centered on 00:00, 03:00, 06:00, 09:00, 12:00, 15:00, 18:00, and 21:00 UTC on 3 August 2012. The precipitation analysis reveals a distinct rainstorm episode on 3 August, during 12:00-21:00 UTC. The plot indicates that TRMM and WRF rainfall estimates are able to capture the rainstorm over Uttarkashi. The simulation is in agreement with the TRMM estimate. However, during 15:00-21:00 UTC, during the cloudburst event, the simulation shows an unrealistically high precipitation event in the southeast portion of the domain. Generation of excessive precipitation in simulation is a major problem in numer- ical weather prediction (Lee et al., 2015). In our case, we speculate that this model artifact was generated due to the orographic effect and the presence of strong moisture divergence.

Thus, TRMM and WRF are able to locate the Uttarkashi cloudburst event geographically as well as by magnitude. The shutting down of convective parametrization in the inner two domains is able to bring out the topographic control over the convective rainstorm process as the convective clouds are well resolved by the innermost domain. As the cloudburst occurred in a relatively data-sparse region, the quality of the initialization field played a major role in the simulation process. Also, the cloudburst process involved rapid intensification and was isolated in nature; therefore an exact match in space and time between simulated and observed rainfall was very difficult. But our space window approach showed that, with a reasonable spatial relaxation, WRF is able to simulate the observed rainfall pattern.

\section{Conclusions}

We examined the meteorological context of a cloudburst event that occurred over Uttarkashi, India, on 3 August 2012. We found that this event is a result of the development of mesoscale convective systems (MCSs) which evolved from diurnally generated convective cells over the Tibetan Plateau and Madhya Pradesh. The persistent $500 \mathrm{hPa}$ flow field directed the MCSs towards the cloudburst site, where they attracted the moisture from the southern part and forced the moisture to move up the slope of the Himalayan mountains. Figure 11 shows our proposed conceptual model of the mechanism of the Uttarkashi cloudburst based on our analysis.

If we compare this cloudburst event with the Leh cloudburst analysis from Rasmussen and Houze (2012), we find some inherent similarities between these two cloudbursts. Both are the result of instabilities that are diurnally generated over the Tibetan Plateau. The southern moisture movement invigorated these storms. The time of monsoon favoured them by providing the moisture-laden meteorological perspective, and the orographic lifting of the unstable air played a major role. There are also differences: the Uttarkashi cloudburst occurred on the wind side of the foothill of Himalayas, which is more natural in the presence of instabilities, whereas Leh is situated on the lee side of the mountain, where rainstorms such as cloudburst are very unlikely. The Leh cloudburst was powered by the MCSs generated over the Tibetan Plateau, whereas the Uttarkashi cloudburst was generated by the interaction of instabilities formed over both Tibet and Madhya Pradesh.

The quantification of complex and nonlinear interaction between orography, moist convection, and cloud microphysics is at a nascent stage. More numerical experiments will shed some light on the process of cloudbursts. If highresolution measurement could be assimilated during the ini- 
tial description of the system, its origination, propagation, and dissipation, then it would improve the simulation results. The measurement of non-assimilated fields will provide a good basis for vigorous evaluation of simulation results. More extensive studies are required to fully understand the cloudburst dynamics, quantify forecasting skill, and develop a strategy for real-time forecasting.

Acknowledgements. The data used in this study are obtained from the Research Data Archive (RDA), which is maintained by the Computational and Information Systems Laboratory (CISL) at the National Center for Atmospheric Research (NCAR). NCAR is sponsored by the National Science Foundation (NSF). The Meteosat-7 satellite imageries are downloaded from the archive of the Cooperative Institute for Meteorological Satellite Studies, Space Science and Engineering Center/University of Wisconsin, Madison. The vertical sounding data are downloaded from Department of Atmospheric Science, University of Wyoming. The authors gratefully acknowledge the NOAA Air Resources Laboratory (ARL) for the provision of the HYSPLIT transport and dispersion model and READY website (http://www.ready.noaa.gov) used in this publication. TRMM data used in this study were acquired from NASA Goddard Earth Sciences (GES) Data and Information Services Center (DISC). We are thankful to Indian Space Research Organisation (ISRO) for providing AWS observations. We want to thank P. Jish Prakash, King Abdullah University of Science and Technology, for his valuable help in conceptualization of the problem addressed in this paper.

The topical editor V. Kotroni thanks two anonymous referees for help in evaluating this paper.

\section{References}

Ashrit, R.: Investigating the Leh "Cloudburst", NCMRWF internel report NMRF/RR/10/2010, Ministry of Earth Science, A-50, Sector-62, Noida-201307, India, 2010.

Borga, M., Stoffel, M., Marchi, L., Marra, F., and Jakob, M.: Hydrogeomorphic response to extreme rainfall in headwater systems: Flash floods and debris flows, J. Hydrol., 518, 194-205, doi:10.1016/j.jhydrol.2014.05.022, 2014.

Bougeault, P., Binder, P., Bizzi, A., Dirks, R., Houze, R., Kuettner, J., Smith, R. B., Steinacker, R., and Volkert, H.: The MAP speacial observing period, B. Am. Meteorol. Soc., 82, 433-462, 2001.

Browning, K.: Structure, mechanism and prediction of orographically enhanced rain in Britain, in: Orographic effects in planetary flows, GARP, 23, 85-114, 1980.

Caracena, F. and Fritsch, J. M.: Focusing Mechanisms in the Texas Hill Country Flash FIOMS of 1978, Mon. Weather Rev., 111, 2319-2332, 1983.

Caracena, F., Maddox, R. A., Hoxit, L. R., and Chappell, C. F.: Mesoanalysis of the Big Thompson Storm, Mon. Weather Rev., 107, 1-17, 1979.

CCI: Census of India 2001: Data from the 2001 Census, including cities, villages and towns (Provisional), Tech. rep., Office of the registrar General and Census Commissioner, India, 2004.
Chen, S.-H. and Lin, Y.-L.: Orographic effects on a conditionally unstable flow over and idealized three-dimensional mesoscale mountain, MAP Newsletters, 15, 246-249, 2001.

Cheng, L.: Mesoscale atmosphere numerical model and simulation, Meteorology Press, Beijing, China, 1994.

Das, S., Ashrit, R., and Moncrieff, M. W.: Simulation of a Himalayan cloudburst event, J. Earth Syst. Sci., 3, 299-313, 2006.

Doswell, C. A.: The operational meteorology of convective weather, NOAA Tech. Rep. ERL ESG-15, NOAA, National Severe Storms Forecast Center, Kansas City, Missouri, 1985.

Doswell, C. A., Brooks, H. E., and Maddox, R. A.: Flash flood forecasting: An ingredients-based methodology, Weather Forecast., 11, 560-581, 1996.

Elliott, R. and Shaffer, R.: The development of quantitative relationships between orographic precipitation and air mass parameters for use in forecasting and cloud seeding evaluation, J. Appl. Meteorol., 218-228, 1962.

Giorgi, F. and Avissar, R.: Representation of heterogeneity effects in earth system modeling: experience from land surface modeling, Rev. Geophys., 35, 413-437, 2010.

Hoskins, B., McIntyre, M., and Robertson, A.: On the use and significance of isentropic potential vorticity maps, Q. J. Roy. Meteor. Soc., 111, 877-946, 1985.

$\mathrm{Hu}, \mathrm{J} .:$ Methods of Generating Surfaces in Environmental GIS Applications, in: International User Conference, ESRI (Environmental Systems Research Institute), ESRI (Environmental Systems Research Institute), San Diego, Ca, USA, 22-26 May, 1995.

Krishbaum, D. and Durran, D.: Factors governing of three dimensional convective storm dynamics, J. Atmos. Sci., 61, 682-698, 2004.

Krishnamurti, T. N., Ardanuy, P., Ramanathan, Y., and Pasch, R.: On the onset of the summer monsoon, Mon. Weather Rev, 109, 344-363, 1981.

Lee, J., Shin, H. H., Hong, S.-Y., Jimenez, P. A., Dudhia, J., and Hong, J.: Impacts of subgrid-scale orography parameterization on simulated surface layer wind and monsoonal precipitation in the high-resolution WRF model, J. Geophys. Res.-Atmos., 120, 644-653, doi:10.1002/2014JD022747, 2015.

Maddox, R. A., Hoxit, L. R., Chappell, C. F., and Caracena, F.: Comparison of meteorological aspects of the Big Thompson flood and Rapid City flash floods, Mon. Weather Rev., 106, 375389, 1978

Mann, C. F. and Kuo, Y.-H.: Regional real time numerical weather prediction: Current status and future potential, B. Am. Meteorol. Soc., 79, 253-263, 1998.

Maraun, D., Wetterhall, F., Ireson, A. M., Chandler, R. E., Kendon, E. J., Widmann, M., Brienen, S., Rust, H. W., Sauter, T., Themeb, M., Venema, V. K. C., Chun, K. P., Goodess, C. M., Jones, R. G., Onof, C., Vrac, M., and Thiele-Eich, I.: Precipitation downscaling under climate change: Recent developments to bridge the gap between dynamical models and the end user, Rev. Geophys., 48, 1-38, 2010.

Medina, S., Houze, J. R. A., Kumar, A., and Niyogi, D.: Summer monsoon convection in the Himalayan region: Terrain and land cover effects, B. Am. Meteorol. Soc., 136, 593-616, 2010.

Nair, U. S., Hjelmfelt, M. R., and Pielke, S. R. A.: Numerical simulation of the 9-10 June 1972 Black Hills Storm using CSU RAMS, Mon. Weather Rev., 125, 1753-1766, 1997. 
NCEP, NWS, NOAA, and USDC: NCEP FNL Operational Model Global Tropospheric Analyses, continuing from July 1999. Research Data Archive at the National Center for Atmospheric Research, Computational and Information Systems Laboratory, updated daily, doi:10.5065/D6M043C6, 2000.

Pielke, S. R. A.: Mesoscale Meteorological Modeling, International Geophysics Series, Academic Press, Inc., 78, 1984.

Rasmussen, K. L. and Houze, J. R. A.: A Flash-Flooding Storm at the Steep Edge of High Terrain: Disaster in the Himalayas, B. Am. Meteorol. Soc, 93, 1713-1724, 2012.

Smith, R. B.: The influence of mountains on the atmosphere, Adv. Geophys., 21, 187-230, 1979.

Stefanon, M., Drobinski, P., D’ Andrea, F., Lebeaupin-Brossier, C., and Bastin, S.: Soil moisture-temperature feedbacks at mesoscale during summer heat waves over Western Europe, Clim. Dynam., 42, 1309-1324, 2014.

Wang, C., Wang, Y., and Wu, R.: The effect of model horizontal resolution on quantitative precipitation forecast for Meiyu front torrential rainfall, J. Hydrodynam., 19, 71-83, 2004.

Wang, C., Wilson, D., Haack, T., Clark, P., Lean, H., and Marshall, R.: Effects of Initial and Boundary Conditions of Mesoscale Models on Simulated Atmospheric Refractivity, J. Appl. Meteor. Climatol., 51, 115-132, 2012.
Webster, P. J.: The Asian Monsoon, in: The coupled monsoon system, edited by: Wang, B., Praxis, Springer, Berlin, Heidelberg, Germany, 1-66, 2006.

Webster, P. J., Magana, V. O., Palmer, T. N., Shukla, J., Tomas, R. A., Yanai, M., and Yasunari, T.: Monsoons: Processes, predictability, and the prospects for prediction., J. Geophys. Res., 103, 14451-14510, 1998.

Webster, P. J., Jian, J., Hopson, T. M., Hoyos, C. D., Agudelo, P. A., Chang, H.-R., Curry, J. A., Grossman, R. L., Palmer, T. L., and Subbiah, A. R.: Extended-range probabilistic forecasts of Ganges and Brahmaputra floods in Bangladesh, B. Am. Meteorol. Soc., 91, 1493-1514, 2010.

$\mathrm{Wu}, \mathrm{G}$. : Evolution of moist potential vorticity and slant wise potential vorticity, J. Meteorol., 53, 387-405, 1995.

Yanai, M. and Li, C.: Mechanism of heating and the boundary layer over the Tibetan Plateau, Mon. Weather Rev, 122, 305-323, 1994. 